\title{
INVESTIGATIONS ON PROPERTIES OF LATEX MODIFIED CONCRETE FOR DIFFERENT STYRENE-BUTADIENE RUBBER DOSAGES
}

\section{A.M.Balasubramaniyan $\#^{1}$}

(Civil Engineering Section, Indian Institute of Astrophysics, Bengaluru 560 034, India.)

\begin{abstract}
This study is an experimental investigation and is being conducted to improve the properties of conventional concrete by partial replacement of water with styrene-butadiene rubber (SBR) to make latex modified concrete (LMC). The SBR partially replaced from $2 \%$ to $8 \%$ at an increment rate of $2 \%$ by weight of water. Suitable super plasticizers are considered for developing LMCss, in combination with SBR, to improve property modifications. Based on the test results, the technical feasibility and performance were assessed. Improvements in the compressive strength, tensile strength, flexural strength and water absorption were observed. The results were compared with plain cement concrete (PCC) at $7^{\text {th }}, 14^{\text {th }}$, and $28^{\text {th }}$ day for compressive strength and other properties were compared during $28^{\text {th }}$ day and it has been discussed.
\end{abstract}

Keywords:Latex modified concrete, Mechanical properties, Styrene Butadiene rubber, Super -plasticizer.

\section{INTRODUCTION}

Concrete is the most widely used man made construction material in civil engineering world. It has specialty of being cast in any desirable shape, but plain concrete however possesses very low tensile strength, limited ductility and little resistance to cracking. As a matter of fact, advancement in concrete technology has been generally on the strength of concrete. Therefore, LMC has been introduced to achieve both strength and durability at the design stage. The LMC has ability of less chloride ions penetration in the concrete when compared to the PCC. The penetrability of concrete is obviously related to the pore structure of the cement paste matrix. This will be influenced by the water-cement ratio of the concrete, the inclusion of supplementary cementing materials which serve to refine the pore structure and the degree of hydration of the concrete.

Latexes are known to affect the physical, mechanical and durability properties of Portland cement paste, mortar and concrete. The magnitude of this effect is dependent on the type of latex and the latex concentration in the mixture. Latexes, most notably those based upon liquid rubber such as SBR, have been employed to dramatically increase the tensile and flexural strength.

A wide variety of super plasticizers have been considered for use, in combination with styrene-butadiene, so as to impart property modifications. In a study, the combination of SBR based super plasticizer has been shown to produce PCC having a better slump retention than Plain cement concrete.

The relevant literature according to Joao A. $\mathrm{R}$ concluded that, interfacial interaction in concrete with silica fume and SBR better results was observed [1], on the other hand, the latex having the highest contents of volatile fatty acids (VFA) and zinc decreases the 
compressive strength about $12.4 \%$ [2], The inclusion of SBR latex in concrete decreases the water-(cement+silica fume) $[\mathrm{W} /(\mathrm{C}+\mathrm{S})]$ ratio \& water absorption and increases the splitting tensile and flexural strengths[3]. In many research properties of the concrete with SBR has shown better strength parameter dramatically [4-8].

\section{EXPERIMENTAL INVESTIGATION}

\section{Materials}

While casting the concrete specimens the ingredients or materials like aggregates, cement, and additives are used, these materials should fulfill the selection criterion as per the IS codes [9-12]. Ordinary Portland Cement (OPC) locally available is used. The cement used for the study was 53grade OPC conforming to IS 12269 (1987) [9]. Natural sand was used as fine aggregate in concrete. The specific gravity and bulk density are 2.64 and $1582 \mathrm{~kg} / \mathrm{m} 3$ respectively. Machine crushed $20 \mathrm{~mm}$ blue granite broken stone angular in shape was used as course aggregate. The specific gravity and bulk density are $2.67,1655 \mathrm{~kg} / \mathrm{m} 3$ and the fineness modulus obtained as 3.6 conducted as per IS 2386-1963 [12]. Potable water free from suspended particles was used for both mixing and curing of concrete. Conforming the water requirements of IS 456-2000[13].

\section{EXPERIMENTAL STUDY}

The compressive, split tensile and flexure tests are conducted by using the Universal Testing Machine (UTM) as per the IS code, sound velocity measurements using PUNDIT and determining the water absorption ratio using temperature controlled Oven [15-20]. The following tests were carried out on the basic ingredient namely cement and aggregates. The tests on coarse aggregate are specific gravity, fineness modulus, bulk density. The tests conducted for cement are specific gravity, standard consistency test, initial and final setting time, compressive test on mortar cube. The proportion and material for making these test specimens are from the same concrete used in the field.

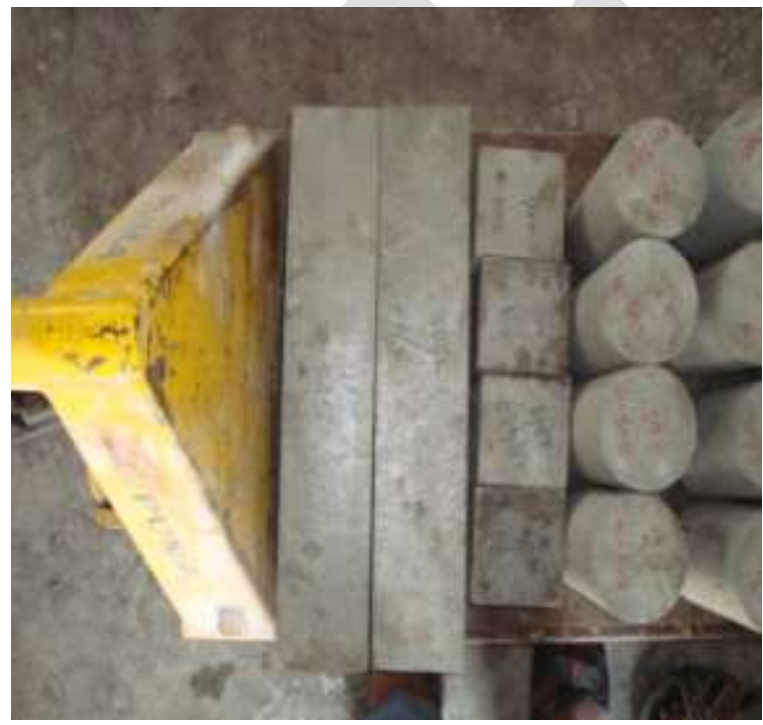

Fig. 1 After casting of the specimens

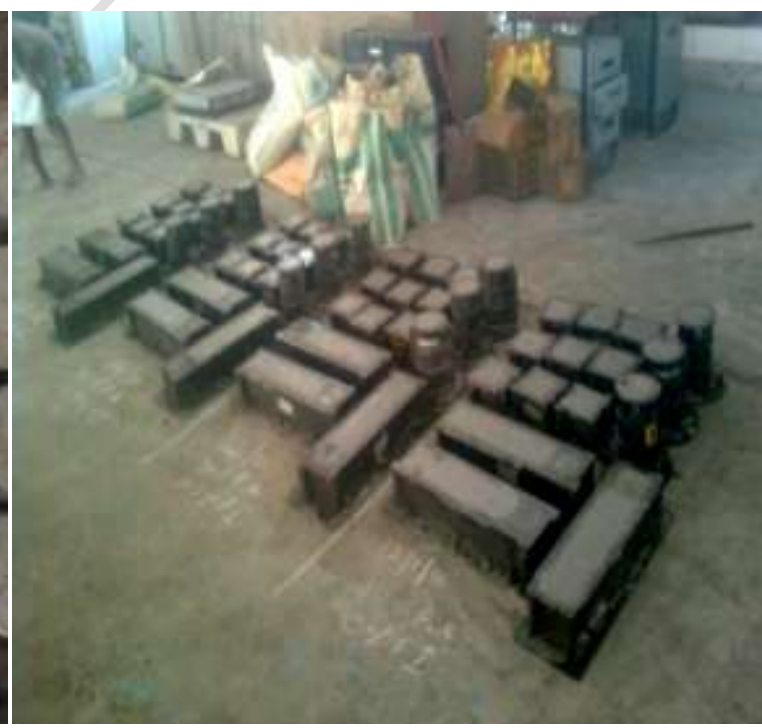

Fig. 2 Specimens after de-molding

\section{DISCUSSIONS}

Strengths obtained for various types of specimens are discussed in the following sub sections. The number 2, 4, $6 \& 8$ mentioned in the tables are the \% of SBR added in the LMC, for example 2 ; it is the $2 \%$ of SBR added in the LMC. 


\subsection{COMPRESSIVE STRENGTH}

The compressive strength of the specimens are tested as shown in fig. 3, results are calculated and listed below in table 1 and 2 and test is conducted for both cube and cylinder, the cylinder strength is converted to cube strength and the graphs are plotted. The area of cube specimen is $10000 \mathrm{~mm}^{2}(100 \times 100 \mathrm{~mm})$

Table 1 Strength of cube specimens tested for different SBR dosages

\begin{tabular}{|c|c|c|c|c|c|c|c|}
\hline \multirow{2}{*}{ Mix ID } & \multirow{2}{*}{ Cubes } & \multicolumn{2}{|c|}{7 days } & \multicolumn{2}{|c|}{14 days } & \multicolumn{2}{|c|}{28 days } \\
\hline & & $\begin{array}{c}\text { Load } \\
(\mathbf{k N})\end{array}$ & $\begin{array}{l}\text { Stress } \\
\text { (MPa) }\end{array}$ & $\begin{array}{c}\text { Load } \\
(\mathbf{k N})\end{array}$ & $\begin{array}{l}\text { Stress } \\
\text { (MPa) }\end{array}$ & $\begin{array}{c}\text { Load } \\
(\mathbf{k N})\end{array}$ & $\begin{array}{l}\text { Stress } \\
\text { (MPa) }\end{array}$ \\
\hline & 1 & 462.25 & 46.23 & 478.8 & 47.88 & 653.45 & 65.35 \\
\hline \multirow[t]{3}{*}{ PCC } & 2 & 418.2 & 41.82 & 492.8 & 49.28 & 597.05 & 59.71 \\
\hline & 3 & 488.9 & 48.89 & 461.6 & 46.16 & 1359.4 & 60.42 \\
\hline & 1 & 459.1 & 45.91 & 557.95 & 55.8 & 662.45 & 66.24 \\
\hline \multirow[t]{3}{*}{ LMC-2 } & 2 & 506.4 & 50.64 & 579.76 & 57.97 & 693.6 & 69.36 \\
\hline & 3 & 201.5 & 46.8 & 529.9 & 52.99 & 595.7 & 59.57 \\
\hline & 1 & דים & 50.4 & 559.3 & 55.93 & 611.7 & 61.17 \\
\hline \multirow[t]{3}{*}{ LMC-4 } & 2 & 511.1 & 51.11 & 563.85 & 56.39 & 638.4 & 63.84 \\
\hline & 3 & 517.75 & 51.78 & 568.05 & 56.81 & 643.15 & 64.32 \\
\hline & 1 & 465.45 & 46.55 & 537.85 & 53.79 & 598.5 & 59.85 \\
\hline \multirow[t]{3}{*}{ LMC-6 } & 2 & 505.95 & 50.6 & 558.85 & 55.89 & 592.05 & 59.21 \\
\hline & 3 & 526.8 & 52.68 & 1232.35 & 54.77 & 1353.99 & 60.18 \\
\hline & 1 & 479.8 & 47.98 & 588.5 & 58.85 & 636.9 & 63.69 \\
\hline \multirow[t]{2}{*}{ LMC-8 } & 2 & 488.25 & 48.83 & 553 & 55.3 & 616.2 & 61.62 \\
\hline & 3 & 540.85 & 54.09 & 594.85 & 59.49 & 657.7 & 65.77 \\
\hline
\end{tabular}


Table 2 Average cube compressive strengths of LMC

\begin{tabular}{ccccccc}
\hline \multirow{2}{*}{$\begin{array}{c}\text { Specimen } \\
\text { type }\end{array}$} & \multicolumn{2}{c}{ Compressive strength (MPa) } & \multicolumn{3}{c}{ \% difference wrt PCC } \\
\cline { 2 - 7 } & 7 days & 14 days & 28 days & 7 days & 14 days & 28 days \\
\hline PCC & 47.56 & 48.58 & 61.82 & - & - & - \\
LMC-2 & 47.78 & 54.77 & 63.38 & 0.46 & 12.74 & 2.52 \\
LMC-4 & 51.1 & 55.91 & 61.97 & 7.44 & 15.09 & 0.24 \\
LMC-6 & 51.64 & 54.81 & 59.74 & 8.58 & 12.82 & -3.36 \\
LMC-8 & 50.3 & 57.88 & 62.05 & 5.76 & 19.14 & 0.37 \\
\hline
\end{tabular}

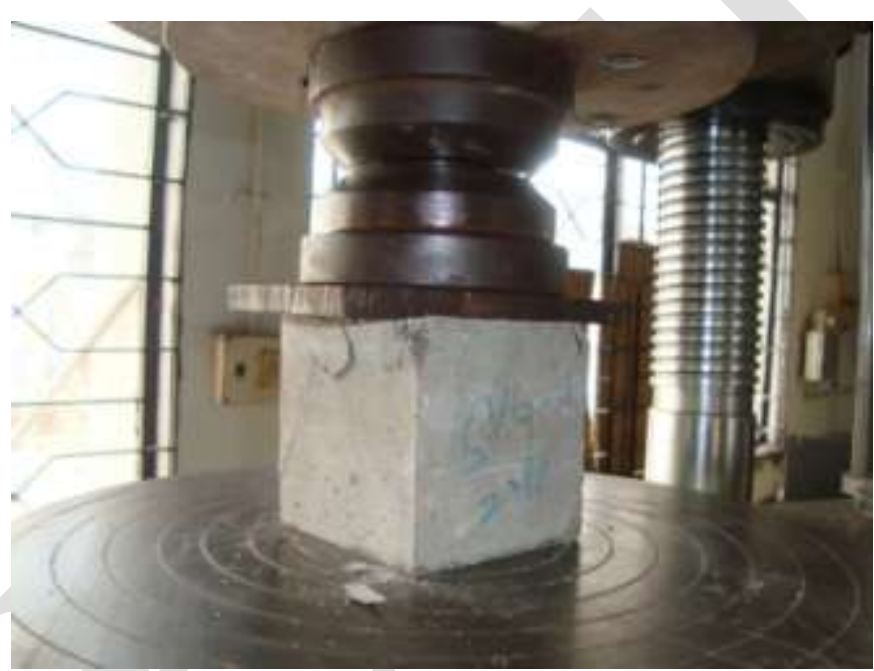

Fig. 3 Cube compression test set up and Crack formation

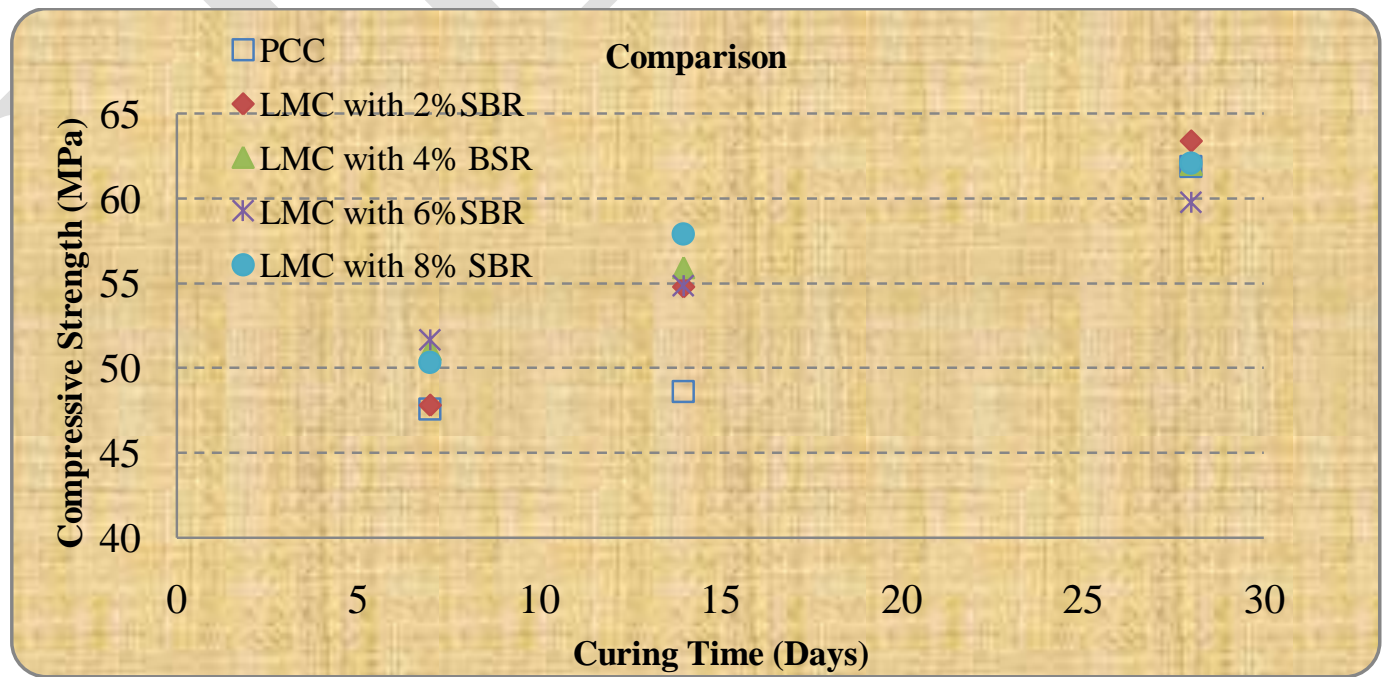

Fig. 4Comparison of compressive strengths for different SBR dosages 


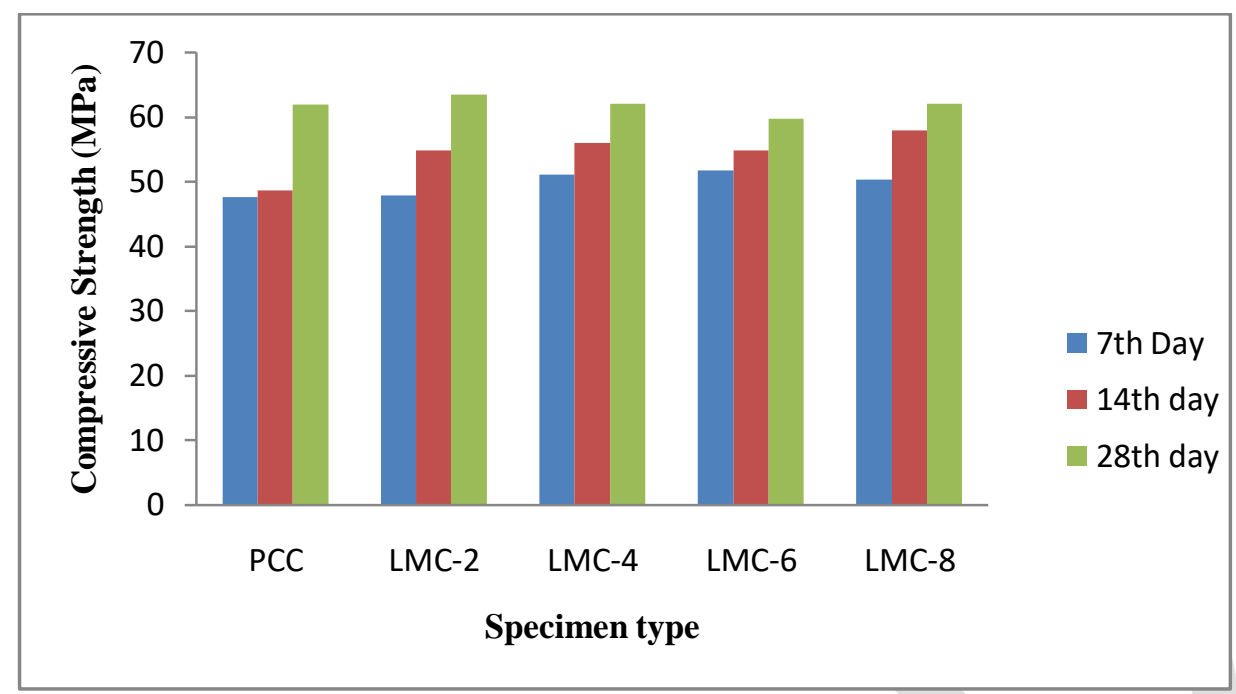

Fig. 5 Compressive strengths at different time (days)

Compressive strength at $7^{\text {th }}$ day for all dosages is increasing with respect to PCC, with in that higher strength is observed in LMC with 6\% SBR dosage (51.64 MPa), percentage difference with respect to PCC is $8.58 \%$ and there is no much difference with other dosages, which is approximately same for all dosages.

LMC with $8 \%$ SBR dosage got the higher strength at $14^{\text {th }}$ day is $(57.88 \mathrm{MPa})$, percentage of increased strength is $19.14 \%$ with respect to PCC and when compare to PCC, all dosages gained the higher strength.

At the $28^{\text {th }}$ day each dosage gained the designed strength except the LMC with $6 \%$ SBR dosage but, at the $7^{\text {th }}$ day this dosage experienced the higher strength. LMC with $2 \%$ SBR dosage gained higher strength (63.38 MPa) when compared to other dosages.

The chart shown in fig. 4 and 5 gives the information about the variation in compressive strength at various time (days) for each SBR dosages.

\subsection{SPLITTING TENSILE STRENGTH}

The splitting tensile strength of the cylinder specimen is testedas shown in fig. 6, results are calculated \&tabulated in the table 3. The area of the cylinder specimen is $7853.98 \mathrm{~mm}^{2}$ (100Ø x200 mm).

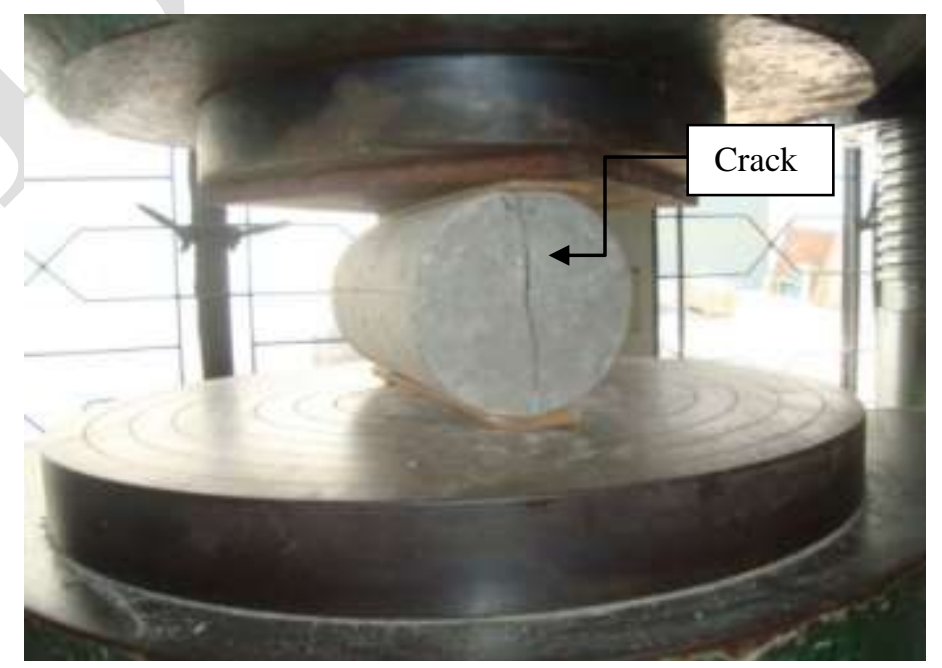

Fig. 6 Split tensile test set up \& crack formation 
Table 3 Specimens tested for different SBR dosages

\begin{tabular}{|c|c|c|c|}
\hline \multirow[t]{2}{*}{ Mix ID } & \multirow[t]{2}{*}{ Specimen } & \multirow{2}{*}{$\begin{array}{c}\text { Tensile Load } \\
\mathbf{k N} \\
\end{array}$} & \multirow{2}{*}{$\begin{array}{c}\begin{array}{c}\text { Split tensile } \\
\text { Strength at } 28 \\
\text { day }\end{array} \\
\mathrm{MPa} \\
\end{array}$} \\
\hline & & & \\
\hline \multirow{4}{*}{ PCC } & 1 & 143.1 & 4.56 \\
\hline & 2 & 138.9 & 4.42 \\
\hline & 3 & 155.75 & 4.96 \\
\hline & 1 & 133.75 & 4.26 \\
\hline \multirow[t]{3}{*}{ LMC-2 } & 2 & 131.5 & 4.19 \\
\hline & 3 & 108.85 & 3.46 \\
\hline & 1 & 136.8 & 4.35 \\
\hline \multirow[t]{3}{*}{ LMC-4 } & 2 & 156.25 & 4.97 \\
\hline & 3 & 130.95 & 4.16 \\
\hline & 1 & 160.76 & 5.12 \\
\hline \multirow[t]{3}{*}{ LMC-6 } & 2 & 173.95 & 5.54 \\
\hline & 3 & 150.72 & 4.8 \\
\hline & 1 & 131.8 & 4.2 \\
\hline \multirow[t]{2}{*}{ LMC-8 } & 2 & 143.15 & 4.56 \\
\hline & 3 & 127.45 & 4.06 \\
\hline
\end{tabular}

Table 4 Average splitting tensile strength

\begin{tabular}{ccc}
\hline Specimen type & $\begin{array}{c}\text { Splitting tensile } \\
\text { strength at 28th } \\
\text { day (MPa) }\end{array}$ & $\begin{array}{c}\text { \% difference wrt } \\
\text { PCC }\end{array}$ \\
\hline PCC & 4.45 & - \\
LMC-2 & 4.22 & -5.16 \\
LMC-4 & 4.66 & 4.72 \\
LMC-6 & 5.15 & 15.73 \\
LMC-8 & 4.38 & -1.57 \\
\hline
\end{tabular}




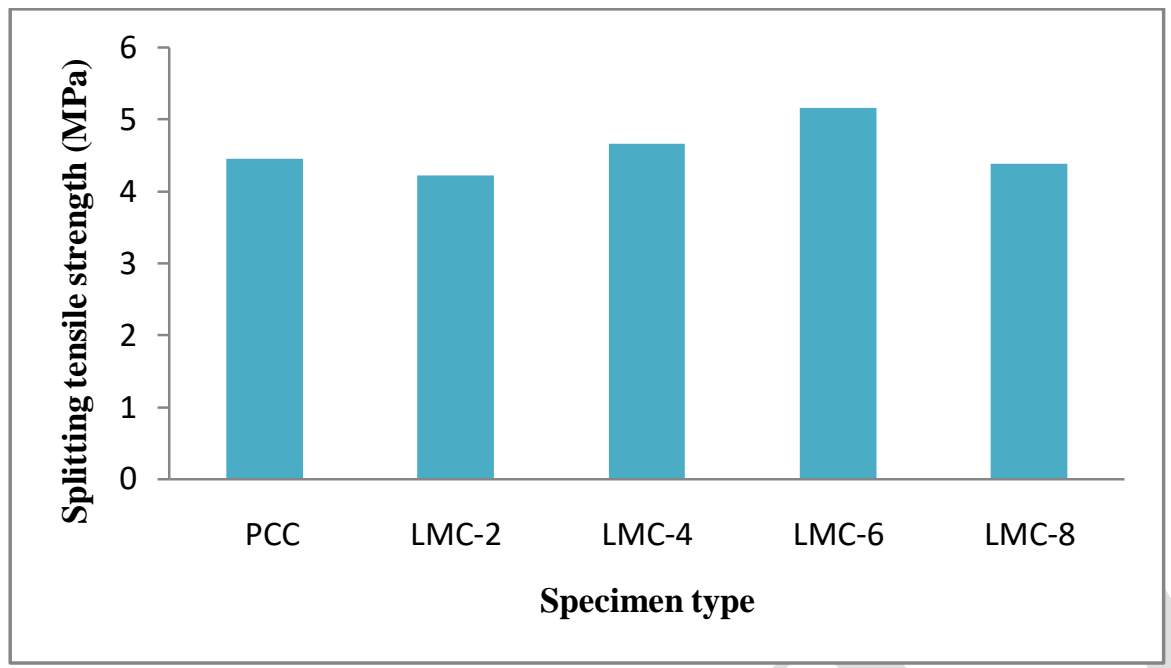

Fig. 7 Split tensile strengths for different SBR dosages

The table $3 \& 4$ shows the details, average splitting tensile strength anddifference in splitting strength with respect to PCC. During splitting tensile strength test it is observed that, expected results has not been achieved, higher results are expected compared to PCC but in test results, LMC with $4 \%$ and 6\% SBR dosages achieved the designed strength (4.66 MPa and $5.15 \mathrm{MPa}$ ). The graphical representationshows the split tensile strengths for different SBR dosages in fig. 7.

\subsection{FLEXURAL STRENGTH}

The flexural strength of the beam specimens is tested, results are calculated and tabulated in the table 5 and 6 . The table shows the details, average flexural strength and $\%$ difference with respect to PCC of the beam specimens at $28^{\text {th }}$ day. Fig. $8 \& 9$ shows the test setup and failure of the specimen. In flexural strength test results achieved the expected results; the strength of each dosage is increased compared to PCC. The higher strength obtained in the LMC with 8\% SBR dosage (7.22 MPa) and the percentage difference with respect to PCC is $16.26 \%$. The fig. 10 \& 11 gives the graphical information about the flexural strength for each SBR dosages compared to the PCC.

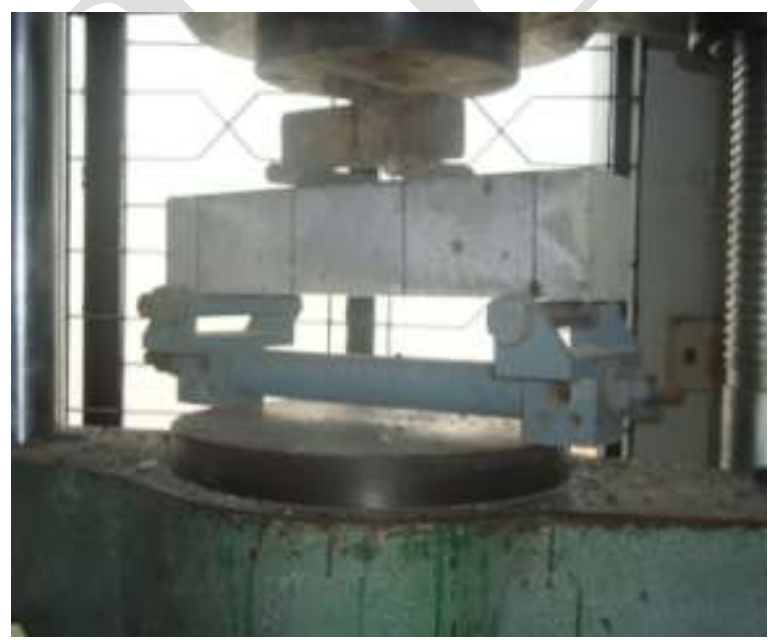

Fig.8 Flexure test set up

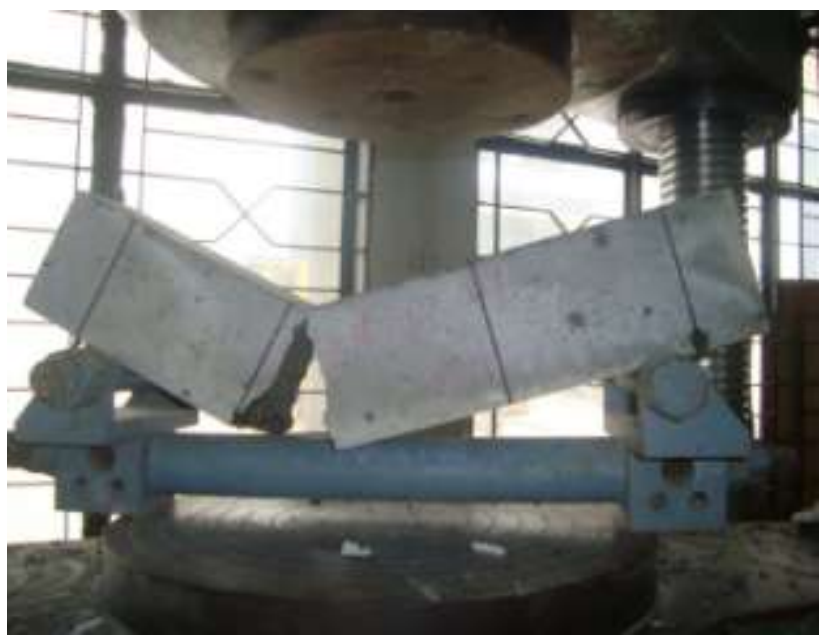

Fig.9 Failure of beam specimen 
Table 5 Specimens tested for different SBR dosages

\begin{tabular}{cccc}
\hline \multirow{2}{*}{ Mix ID } & Specimen & Failure Load & $\begin{array}{c}\text { Flexure } \\
\text { Strength at } \\
\text { 28th day }\end{array}$ \\
\cline { 3 - 4 } & & $\mathbf{k N}$ & $\mathbf{M P a}$ \\
\hline \multirow{2}{*}{ PCC } & 1 & 15.7 & 6.28 \\
& 2 & 15.35 & 6.14 \\
LMC-2 & 1 & 15.5 & 6.2 \\
& 2 & 17.3 & 6.92 \\
LMC-4 & 1 & 16.35 & 6.54 \\
& 2 & 18.25 & 7.3 \\
LMC-6 & 3 & 16.45 & 6.58 \\
& 1 & 17.2 & 6.88 \\
LMC-8 & 1 & 16.65 & 6.66 \\
& 2 & 17.45 & 6.98 \\
& 3 & 18.65 & 7.46 \\
\hline
\end{tabular}

Table 6 Average flexural strength

\begin{tabular}{|c|c|c|}
\hline $\begin{array}{c}\text { Specimen } \\
\text { type }\end{array}$ & $\begin{array}{c}\text { Flexural } \\
\text { strength at } \\
\text { 28th day } \\
\text { (MPa) }\end{array}$ & $\begin{array}{c}\text { \% difference } \\
\text { wrt PCC }\end{array}$ \\
\hline PCC & 6.21 & - \\
\hline LMC-2 & 6.56 & 5.64 \\
\hline LMC-4 & 6.81 & 9.66 \\
\hline LMC-6 & 6.88 & 10.79 \\
\hline LMC-8 & 7.22 & 16.26 \\
\hline
\end{tabular}

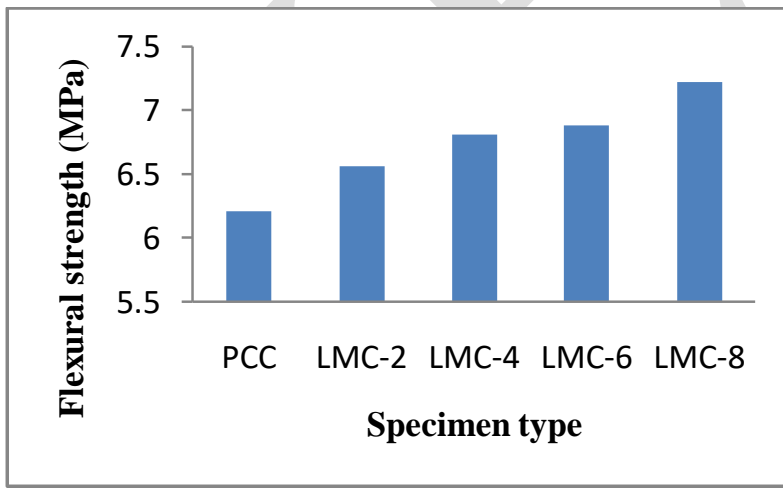

Fig. 10 Comparison of Flexural strengths for different SBR dosages

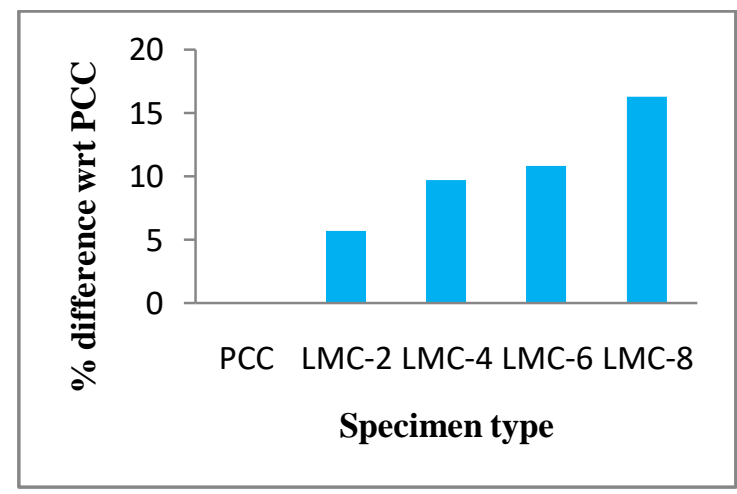

Fig.11\% difference of flexural strengthswrt PCC

\subsection{SOUND VELOCITY MEASUREMENT}

The sound velocity measured using ultrasonic pulse velocity (UPV) as shown in figure 12, the specimens are tested and values are calculated and shown in table 7 and 8. 


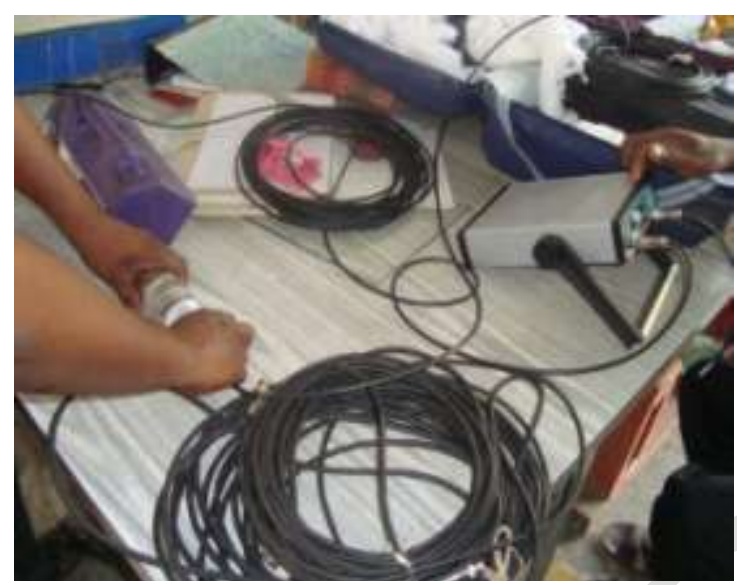

Fig.12 Measurement of sound velocity

Table 7 List of specimens tested for different SBR dosages

\begin{tabular}{ccc}
\hline Pundit & Specimen & $\begin{array}{c}\text { Speed } \\
\text { velocity } \\
\text { Mix ID } / \mathbf{s})\end{array}$ \\
\hline \multirow{2}{*}{ PCC } & 1 & 4761.90 \\
& 2 & 5000.00 \\
& 3 & 4761.90 \\
LMC-2 & 1 & 4761.90 \\
& 2 & 5000.00 \\
LMC-4 & 3 & 4651.16 \\
& 1 & 4761.90 \\
LMC-6 & 1 & 4761.90 \\
& 2 & 4761.90 \\
LMC-8 & 3 & 4761.90 \\
\hline
\end{tabular}

Table 8 Average sound Velocity

\begin{tabular}{ccc}
\hline $\begin{array}{c}\text { Specimen } \\
\text { type }\end{array}$ & $\begin{array}{c}\text { Velocity at } \\
\text { 28th day } \\
\text { (m/Sec) }\end{array}$ & $\begin{array}{c}\text { \% of } \\
\text { decrease in } \\
\text { velocity } \\
\text { wrt PCC }\end{array}$ \\
\hline PCC & 4880.95 & - \\
LMC 2\% & 4804.35 & 1.59 \\
LMC 4\% & 4761.90 & 2.50 \\
LMC 6\% & 4761.90 & 2.50 \\
LMC 8\% & 4761.90 & 2.50 \\
\hline
\end{tabular}




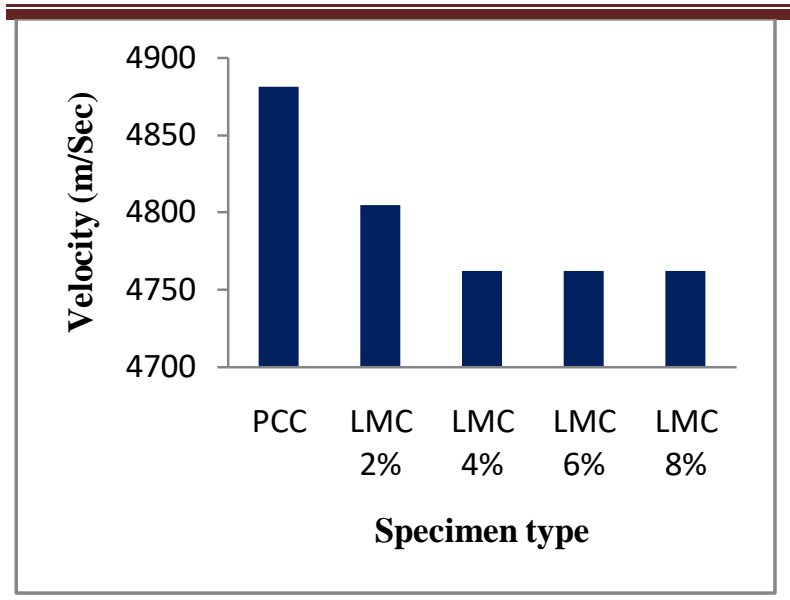

Fig. 13 Comparison sound velocity for different SBR dosages

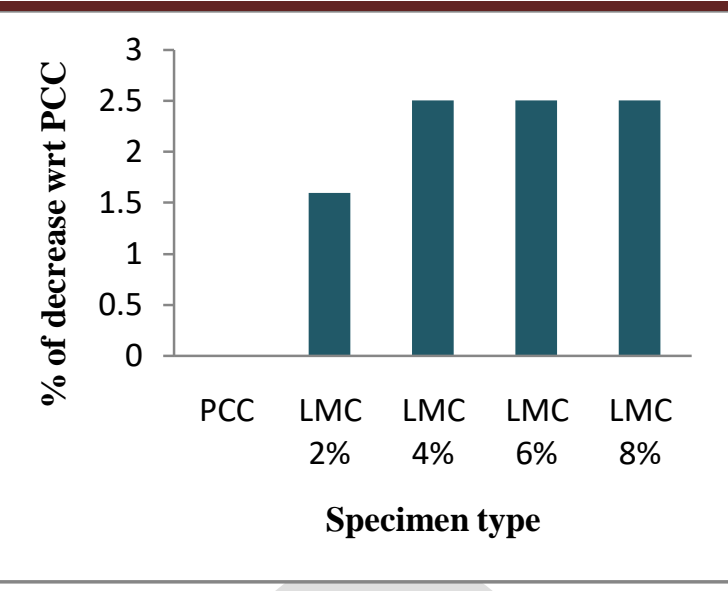

Fig. $14 \%$ decrease in velocity wrt PCC

The table 7 and 8 is shows the sound velocity measurements and \% difference with respect to PCC of specimens at 28th day. The lesser values sound velocity is observed for all SBR dosages compared to the PCC, in that higher test result value is $4880.95 \mathrm{~m} / \mathrm{sec}$ in PCC. All dosage results are greater than the $4500 \mathrm{~m} / \mathrm{sec}$, so in each dosage the concrete specimen is good quality and no air voids or minor cracks in the specimens as per guidelines for concrete quality based on UPV as shown in table 9. This test is the one of the type of non destructive evaluation (NDE) test for the concrete specimens. From fig.14 we can easily identify the difference of sound velocity for the different SBR dosages.

Table 9 General Guidelines for Concrete Quality based on UPV

\begin{tabular}{|l|l|}
\hline \multicolumn{1}{|c|}{ Pulse Velocity } & \multicolumn{1}{c|}{ Concrete Quality } \\
\cline { 2 - 3 } $3000 \mathrm{~m} / \mathrm{s}$ & Very good to excellent \\
\hline 3500 to $4000 \mathrm{~m} / \mathrm{s}$ & $\begin{array}{l}\text { Good to very good, slight } \\
\text { porosity may exist }\end{array}$ \\
\hline 3000 to $3500 \mathrm{~m} / \mathrm{s}$ & $\begin{array}{l}\text { Satisfactory but loss of } \\
\text { integrity is suspected }\end{array}$ \\
\hline$<3000 \mathrm{~m} / \mathrm{s}$ & $\begin{array}{l}\text { Poor and los of integrity } \\
\text { exist. }\end{array}$ \\
\hline
\end{tabular}

\subsection{WATER ABSORPTION}

The percentage of water absorption test of the specimens is conducted, values are calculated and results are shown in table 10 and 11. The tables show the percentage water absorption and $\%$ difference with respect to PCC of specimens at $28^{\text {th }}$ day.Inthis test achieved an expected results, the percentage of water absorption is decreasing when percentage of SBR increased.The LMC with $8 \%$ SBR dosage got the higher water resistance compared to all dosages and the percentage difference is $38.64 \%$ compared to PCC.The PCC absorbs more water when compared to other dosages. The graph shown in fig. 17 for the percentage of water absorption of different SBR dosages. 


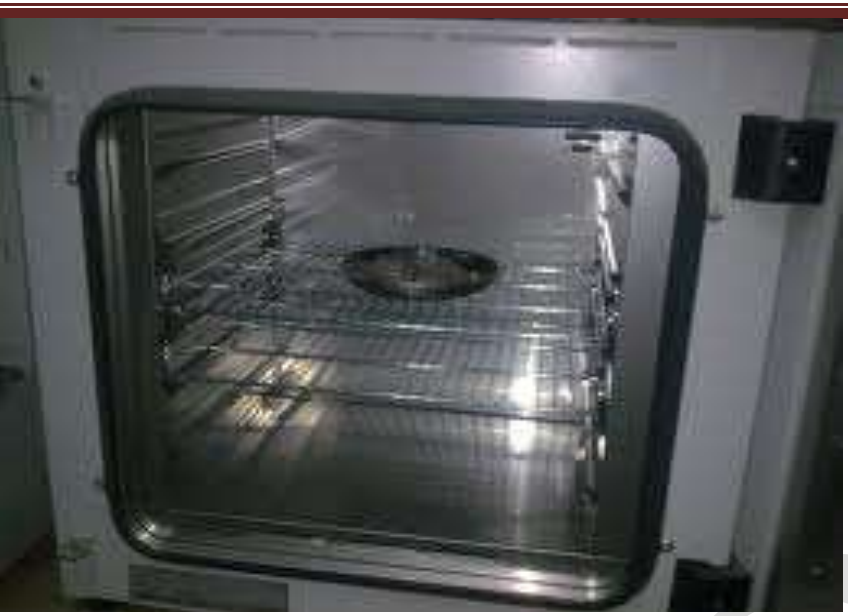

Fig.15 Temperature controlled oven

Table 10 List of specimens tested for different SBR dosages

\begin{tabular}{ccccc}
\hline Mix ID & Specimen & $\begin{array}{c}\text { Weight of } \\
\text { specimen after } \\
\text { water } \\
\text { absorption(Kg) }\end{array}$ & $\begin{array}{c}\text { Oven } \\
\text { dried } \\
\text { weight } \\
\text { (Kg) }\end{array}$ & $\begin{array}{c}\text { \% water } \\
\text { absorption }\end{array}$ \\
\hline \multirow{2}{*}{ PCC } & 1 & 2.55 & 2.48 & 2.82 \\
& 2 & 8.31 & 8.15 & 2.05 \\
LMC-2 & 1 & 3.95 & 3.87 & 2.25 \\
& 2 & 3.94 & 3.85 & 2.29 \\
LMC-4 & 1 & 2.47 & 2.42 & 2.11 \\
& 2 & 2.46 & 2.42 & 1.95 \\
LMC-6 & 1 & 2.50 & 2.44 & 2.13 \\
& 2 & 8.43 & 8.28 & 1.70 \\
LMC-8 & 1 & 2.54 & 2.49 & 1.93 \\
& 2 & 8.48 & 8.34 & 1.59 \\
\hline
\end{tabular}

\section{Specimen \\ type}

PCC

LMC $2 \%$

$\mathrm{LMC} 4 \%$

LMC 6\%

LMC $8 \%$

Table 4.11 Average \% water Absorption

Water absorption at 28th day (\%)

2.44

2.27

2.03

1.92

1.76
$\%$ of decrease

in water

absorption wrt

PCC

7.49

20.2

27.08

38.64 


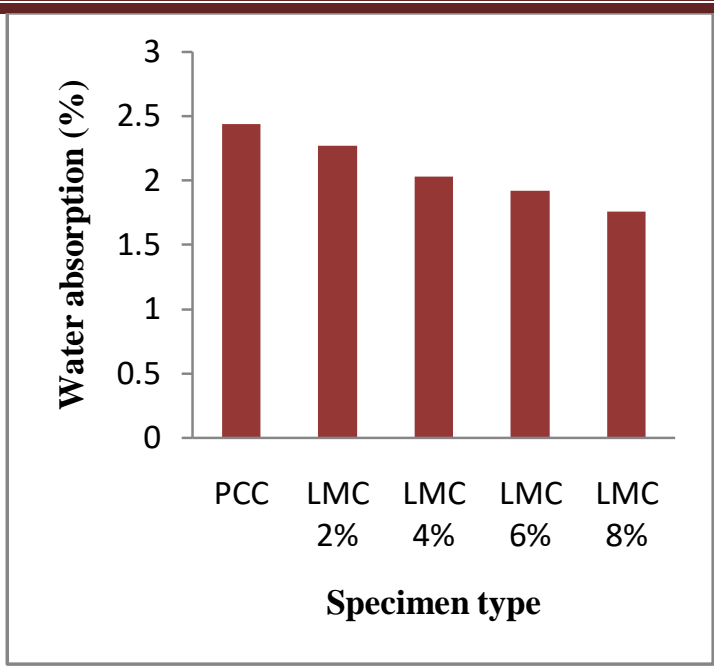

Fig. 16 Comparison water absorption for different SBR dosages

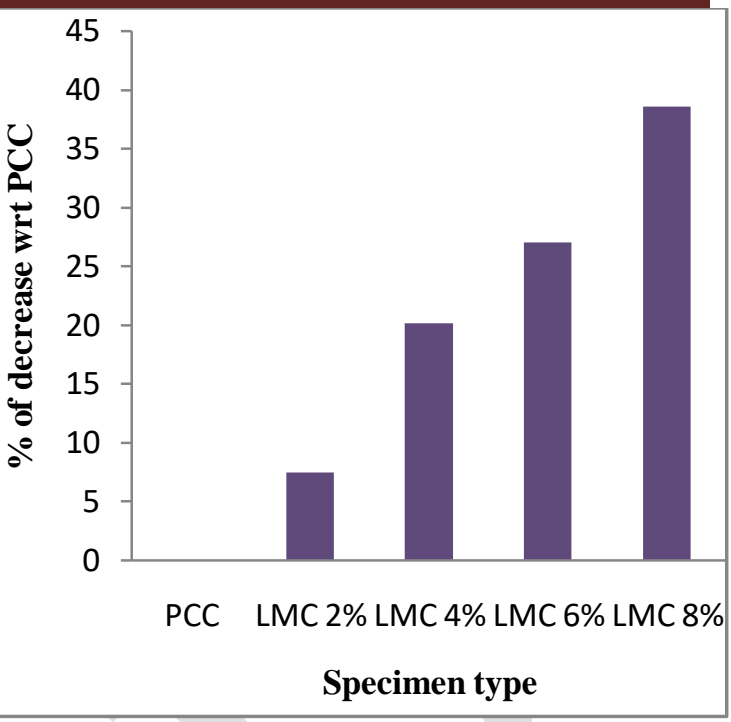

Fig. 17\% decrease in water absorption wrt PCC

\section{SUMMARY AND CONCLUSIONS}

The tests are conducted at advanced material laboratory at Council of Scientific and Industrial Research(CSIR) -Structural Engineering Research Centre(SERC) -Tharamani, Chennai. Various specifications given by ASTM and BIS standards regarding test methods for materials and concrete were followed as already discussed. Based on the test results and observations made during the experimental study, the results are summarized here. The comparison made between LMC and PCC is useful for the design engineers involved in the repair and retrofitting work. The following conclusions may be drawn from the presented study in this document:

1. As reported in literature that with the increase in percentage concentration of SBR in LMC compressive strength reduces. However it is found that there is no significant change in 28 days compressive strength and about 2 to $5 \%$ increase in the compressive strength is acquired.

2. In comparison to PCC, LMC gains higher strength in 7, 14 and 28 days after curing.

3. The split tensile strength of the specimen is higher in LMC with 6\% SBR dosage $(5.15$ $\mathrm{MPa}$ ). The split tensile test results are not achieved desired strength as we expected when compare to the PCC. The split tensile strength of the cylinder specimen results is about 7 to $10 \%$ of the compressive strength of the cube specimen.

4. Flexural strength of the beam results achieved expected improvement for all dosages of SBR as compared to the PCC. The maximum flexural strength was obtained for LMC with $8 \%$ SBR dosage $(7.22 \mathrm{MPa})$. In this studywhen increase in percentage of concentration of SBR in LMC, increaseof flexural strength is observed. The flexural strength of the beam specimen is obtained about $10 \%$ to $13 \%$ of the compressive strength.

5. Sound velocity test is commonly used for health assessment of existing structures through non destructive evaluation (NDE). In the present study sound velocity is represented as ultrasound pulse velocity. For increased SBR dosages in LMC the sound velocity is found to decrease as compare to the PCC. The maximum sound velocity obtained in PCC is $4880.95 \mathrm{~m} / \mathrm{sec}$. However all the dosage of SBR has shown sound velocity more than the $4500 \mathrm{~m} / \mathrm{sec}$, which indicates concrete quality is excellent. It means with all SBR dosages, the LMC specimen has no voids. 
6. The water absorption of specimens is reducing with increase in SBR content. The lesser water absorption, lesser voids, high strength $\&$ durable and if, higher water absorption more voids \& lesser strength in concrete. Higher water resistance is acquired in LMC with $8 \%$ SBR dosage. Normally good quality of concrete specimen absorbs less water. The water absorption is low for LMC with $8 \%$ SBR dosage $(1.76 \%)$.

7. In the present study SBR dosage effect in the range of $2-8 \%$ is studied. Further studies may be carried out to understand the effect of SBR dosages in the range higher than $8 \%$.

\section{REFERENCES}

1. Joao A. R., (2009), Interfacial interactions in concretes with silica fume and SBR latex, Construction and Building Materials, vol.23, Apr, pp.817-821.

2. Bala M., Ismail M., Aamer M., Rafique B. and Abdul-Majid Z., (2012), Influence of non-hydrocarbon substances on the compressive strength of natural rubber latexmodified concrete, Construction and Building Materials, vol. 27, pp.241-246.

3. Joao A. R. and Marcos V.C.A, (2002), Mechanical properties of polymer-modified lightweight aggregate concrete, Cement and Concrete Research, vol.32, Aug, pp.329334.

4. Adnan C., (2004), Properties of plain and latex modified Portland cement pastes and concretes with and without super plasticizer, Cement and Concrete Research, vol.35, Nov. pp.1510- 1521.

5. Bala M. and Ismail M., (2012), Performance of natural rubber latex modified concrete in acidic and sulfated environments, Construction and Building Materials, vol.31, pp.129-134.

6. Shaker F.A., El-Dieb A.S., and Reda M.M., (1997), Durability of styrene-butadiene latex modified concrete, Cement and Concrete Research, vol.27, No.5, March, pp.711720.

7. Barluenga G., Hernandez-Olivares F., (2004), SBR latex modified mortar rheology and mechanical behavior, Cement and Concrete Research, vol.34, September, pp. 527-535.

8. Okba S.H., El-Dieb A.S and Reda M.M., (1997), Evaluation of the corrosion resistance of latex modified concrete (LMC), Cement and Concrete Research, vol.27, Apr, pp.861-868.

9. IS: 12269-2013, Ordinary Portland cement, 53 Grade-Specification, BIS, New Delhi.

10. IS 383:2016, coarse and fine aggregate - specification, BIS, New Delhi.

11. IS: 4031-1988, Methods of physical tests for hydraulic cement, BIS, New Delhi.

12. IS: 2386-1963, Methods of test for aggregates for concrete Part 1 Particle size and shape, BIS, New Delhi.

13. IS 456:2000, Plain and reinforced concrete- Code for practice, BIS, New Delhi.

14. IS: 10262-1982, Recommended guidelines for concrete mix design, BIS, New Delhi.

15. IS: 516-1959, Method of test for strength of concrete, BIS, New Delhi.

16. BS 1881: Part 116:1983 and ASTM: C 39/C 39m, Method of Compressive strength test

17. IS: 5816: 1999 Splitting tensile strength of concrete method of test, BIS, New Delhi.

18. BS 1881: Part 118: 1983, Flexure strength of concrete method of test.

19. IS: 13311 (Part 1): 1992, Method of velocity measurement of test, BIS, New Delhi.

20. ASTM C642-81, Method of water absorption test. 